\title{
FIBROSITIS AND REALITY
}

\author{
BY \\ MICHAEL KELLY \\ Perth, Western Australia
}

The following personal experience may throw some light on the problems of fibrositis. In March 1935, the writer contracted scarlet fever, the attack was a mild one and recovery appeared to be complete within a few days. Eighteen days after the onset, however, the heels became sore after walking 100 yards on a hard surface with a vivid impression of thickening of the soft tissues, but no swelling was discernible. A few days later spontaneous pains developed in the shoulders, at first inconstant and fleeting but soon becoming more continuous. The pain was felt over the greater tuberosity of the humerus and along the anterior border of each deltoid muscle; no tenderness, swelling or induration of any kind was detected. Bicipital tenosynovitis was diagnosed. If the shoulders were kept at rest little pain was felt for a few minutes; then they would begin to ache and become painfully stiff, and change of position became imperative. Abduction of the humerus was extremely painful for a range of about 30 degrees. The shoulders ached more at night than during the day and were painfully stiff on waking; with use the stiffness would wear off. All movements involving abduction or forward flexion against slight resistance were painful.

Inconstant pains were felt in the lumbar region and the hips and in the knees for a time, but after a few weeks the knees became the seat of a constant disability similar to that in the shoulders, aching more or less continuously, worse at night, the pain being felt mainly on the inner side of the joint from the upper border of the femoral condyle to the lower border of the tibial condyle. There was no tenderness or swelling and no limitation of movement. After walking a few yards weight bearing became painful but was relieved by flexing the joints slightly; unbearable cramps in the thighs occurred if the knees were held in one position continuously. The wrists became painfully stiff so that ordinary movements could not be performed, but again there was no swelling or obvious tenderness.

For five weeks I attempted to carry on, but then went to bed in hospital for a month. The inactivity, however, increased the stiffness without contributing to recovery. Tonsillectomy was performed without any apparent benefit. Diathermy relieved the pain in the knees and shoulders but only for the duration of the treatment, and after it the pain would be worse and the treatment was abandoned after two weeks.
A rigor was induced with B.C.C. but without evident improvement. Thirty c.cm. of scarlatinal antistreptococcal serum were given on admission to hospital; this was followed by general urticaria lasting four days. The temperature was never raised except during the initial attack of scarlet fever and during the artificial rigor. Red and white cell counts were normal, there was no muscular wasting or loss of weight nor any lack of appetite. I had never suffered from rheumatic disease previous to this attack.

I visited a bee farm and allowed myself to be stung on the forearms more than a dozen times without relief. Four weeks after leaving hospital I noticed an improvement in knees and shoulders, and within a fortnight all trace of pain had disappeared; I cannot attribute this recovery to any known cause.

The chief features of this illness were the deepseated pain without tenderness associated with feebleness and lack of muscular co-ordination and severe cramps, possibly due to irregular muscular contractions of reflex origin. A vivid recollection is the baneful effect of cold in fibrositis, I became extremely sensitive to draughts. This effect was not due to a lowering of body temperature but to increased cold-sensitivity in the skin, and this lasted for several years.

\section{Light Shed by Recent Advances}

Lately I have come to regret that I was not at that time possessed of some recently acquired knowledge relating to fibrositic nodules and to referred pain from muscles. I have no doubt that examination by careful palpation would have revealed deep lesions, not in the painful areas but in adjacent muscular tissue. The preliminary work of J. H. Kellgren (1938) suggested that fibrositic lesions had a predilection for certain sites, and that the resultant pain tended to radiate in remarkably regular patterns. This has now been confirmed by a large number of observers, and in many hundreds of cases by the present writer (Kelly, 1941a, b; 1944a, b, c; $1944 a, b, c)$.

The "painful shoulder" comprises a variety of conditions whose detailed description is not my purpose. Suffice to say that in all of them the pain tends to radiate in a constantly recurring pattern. 
and that in the majority the offending lesion is situated not in the deltoid but in the muscles attached to the scapula, usually the upper fibres of the trapezius, the supraspinatus, or the infraspinatus. Local anaesthetic injected into this site abolishes the pain, and the relief in a surprising number is permanent (Kelly, 1942b). Almost identical results have been reported by Travell, Rinzler, and Herman (1942).

With fibrositis of the knee the tendency is for the formation of lesions in adjacent soft tissues, usually in relation to the upper border of the internal condyle of the femur or in the calf muscles behind the inner tibial condyle (Kelly, 1944b). Local anaesthetic accurately injected into the right spot will cause an immediate striking amelioration of symptoms; frequently the improvement is lasting. Similar results have been reported by Dally (1940) and Good (1942a, b). Many writers can be quoted who recognized that pain in the knees could proceed from lesions in the soft tissues (Mennell, 1938; Telling, 1935; Kellgren, 1939).

\section{Psychogenic Fibrositis}

To different observers fibrositis bears varying degrees of reality. A comprehensive synonym is " non-articular rheumatism"; but the lack of a precise definition of "rheumatism" still leaves the situation far from clarified. Any somatic pain which is not accompanied by well-defined physical signs of disease may therefore come under the general designation of " fibrositis." By some observers, pains which do not conform to certain well-recognized patterns are regarded as psychogenic. Many cases which some physicians diagnose as fibrositis would therefore be considered by others as psychosomatic in origin. Thus to Halliday (1941, 1942) the pain, stiffness, and soreness in the majority of cases are symbolical, signifying the patient's lack of harmony with his surroundings. Ellman, Savage, Wittkower, and Rodger (1942), however, thought that well-defined muscular tenderness indicated an organic basis for the pain, and, where this sign was lacking, they usually were able to elicit a history of psychological upset.

Many others could be quoted. It is in fact almost universal to regard as nervous those pains which cannot be made to harmonize with accepted neurological theory. It has been so for many years; it was noted by the poet Keats more than a hundred years ago that " if the doctors cannot ascertain a disease they call it nervous." But simple assertions will not suffice; a recognizable etiological chain should be established if the psychogenic origin of pain is to be accepted as a scientific fact. Bramwell (1930), who wrote upon psychogenic pain, was taken to task by Walshe (1930), who denied that these so-called pains were pains at all. Pain, says Walshe, cannot even be imagined; what the patient feels in these cases is a mental distress which he incorrectly labels pain.

\section{The Alternatives}

Where then lies the truth? When a patient complains of shifting pains for which no cause can be ascertained, we have the option of at least four explanations:

1. The pain symbolizes mental distress, or is resorted to as a refuge from difficulties; therefore it is hallucinatory.

2. The patient mistakenly labels as pain a totally different unpleasant sensation.

3. The patient really has pain, the direct effect of psychic central disturbance upon the body tissues.

4. The patient really has pain, which is not psychogenic but somatic in origin.

I am leaving out the possibility of deliberate simulation, or malingering. Evidence of mental distress is held to enhance the likelihood of a psychogenic origin. It should not be forgotten, however, that long-continued pain of itself will cause mental distress and nervous exhaustion, which then could erroneously be regarded as the cause of the pain. In searching a patient's past for evidence of " psychic trauma," it should be remembered that in the life of almost every normal person there occur mental conflicts which by an enthusiastic psychiatrist might be elevated to a prime cause of psychosomatic disease.

\section{Hallucinations of Pain?}

Before accepting as a likely explanation symbolical or hallucinatory pain occasioned by present mental distress or past mental conflicts, we should ask ourselves some questions regarding hallucinations of pain. If they are common in the sane, why do they differ so profoundly in this regard from other hallucinations, which are pathognomonic of insanity or of serious toxic disease? There is a large subjective element in pain which is appreciated only by the sufferer, who very often can produce no evidence of its existence beyond the mere assertion that he feels it. Pain therefore lends itself readily to simulation or exaggeration, but there is no evidence that it thereby becomes more readily the subject of hallucinations or delusions. Solomon (1917), who reviewed the subject at length, concluded that " an idea of a pain can by no manner of means evoke a pain." Walshe (1930) agrees that there is no such thing as subjective pain; he thinks that the patient is suffering from a kind of delusion in interpreting mental distress as pain. In dealing with such intangible matter, however, there would appear to be very little difference between imagining a pain and conjuring up a pain out of a different sort of feeling.

There is no real evidence, in fact, that the vast majority of patients who complain of pain do not actually feel the pain. The onus of disproof is on the observer in every case; he cannot whisk it away by a mere assertion. The fact that the distribution of the pain does not correspond with accepted patterns does not necessarily mean that it has no reality; it is more likely to mean that our knowledge of pain is inadequate. Recent work on deep pain, in fact, suggests that "vague," shifting, poorly 
localized pain, accompanied by little anatomical change, may be a feature of many somatic ills. More detailed study of such cases, by questioning and palpation, often reveals constantly recurring patterns of pain-radiation and of tender spots in the deeper tissues. Much that was obscure in fibrositis has been illuminated in the past six years, and one can hopefully expect that further studies, based upon the same scientific foundation, will give greater reality to that which still remains obscure.

\section{Causation}

We must assume, therefore, that our patient if he is not malingering really has a pain, "peripherally induced and subjectively appreciated" (Solomon); for want of a better term we label this pain " fibrositis." Very occasionally such an illness begins soon after a severe nervous shock such as a bereavement, or during a period of nervous exhaustion. The question then arises as to the nature of the links in the chain of causation; for all students of rheumatism are agreed that such a succession of events occurs a little too often for mere coincidence. Any type of rheumatic disease, even profound rheumatoid arthritis, may follow severe mental strain.

Considering rheumatic etiology in general, it is probably true that in rheumatic disease of whatever variety the onset can be traced in more than a third of the cases to a particular event, such as infection, injury, or muscle-strain. Thus rheumatic fever frequently follows a sore throat after a silent interval; fibrositis often is brought on by a chill or by an injury; dysentery and many other infectious diseases have recognized rheumatic sequelae; and so on. In my own case, generalized fibrositis followed scarlet fever after a silent period of about a fortnight. There can be no doubt whatever that the fibrositis was etiologically linked to the infection; but the links in the chain are unknown. It is indisputable that the attack of scarlatina must have initiated certain changes in the system which became progressive, and after two weeks manifested themselves as generalized pains. A study of the history of a number of rheumatic cases will reveal a similar chain of events: a general or local infection, an injury or a chill; an injection of T.A.B., or almost any other illness may be the initiating event which sets the pathological process in motion. It is nearly true to say that any form of injury to body cells may be followed by rheumatism. Severe nervous strain comes under this category of injury or insult to the tissues; for exhaustion, great anxiety or grief, or any similar strain, occasions disorder of the cells of the central nervous system even as a chill occasions disorder of the cells of the somatic tissues.

\section{Rheumatism and the Nervous System}

In the following case, seen by the writer, organic disorder of the central nervous system was an unmistakable causative factor in joint disease: A man, aged 46, developed Huntington's chorea in its worst form, and died within one year of its onset. During the last six months, while he was bedridden and com- pletely irrational, changes typical of rheumatoid arthritis developed in his knees, ankles, elbows, and wrists. The bone ends became enlarged and tender, with fluid in the joints. Advanced contractural deformities developed, with muscular wasting.

In a similar case reported by de Haas (1941), a patient became deeply cyanotic during anaesthesia and his breathing was arrested. Within a few weeks he developed Parkinsonian tremor, followed by a typical picture of rheumatoid polyarthritis.

If central nervous disease, as in the above cases, is certainly responsible for profound joint changes, it cannot be denied that a related but more transient etiological factor ought sometimes to be responsible for less severe rheumatic symptoms, such as fibrositis. There should be no more mystery, therefore, about fibrositis when it follows nervous exhaustion than when it follows an infection. Rheumatism is etiologically linked to cerebral dysfunction, even as it is linked to infection of the respiratory tract, by a chain of pathological processes whose nature is unknown. The fact that fibrositis sometimes is psychogenic should render it neither more nor less explicable than when it is due to other causes. Once the process has been set in motion, the removal of the original causative factor is by no means certain to reverse it. Thus, in my case, the pains were not felt until some time after I had fully recovered from scarlet fever; fibrositis which follows an injury or exposure to cold will proceed in spite of the healing of the injury or recovery from the chill. Hence the generai failure to cure rheumatism by removal of foci of infection. The infection which initiates the rheumatic process is not of necessity instrumental in its continuance, for an additional unknown factor has begun to act.

Similarly, when rheumatism follows nervous exhaustion the disorder of the cells has initiated a process which then comes under the control of unknown factors. Recovery of the nerve cells (whether in the course of nature or with the aid of psychotherapy) could not always be expected to result in the cure of the rheumatic process, even as recovery from a sore throat has no relation to the cessation of an attack of rheumatic fever.

If this thesis be true, the fibrositis which follows nervous exhaustion is just as real as that which follows any other cause, or the cause of which is unknown. The uncovering of a psychic cause will render the disease neither more nor less explicable, and the disappearance of the nervous disorder should not be expected to bring about certain cure. The psychogenic factor, in order to be significant, should be as unmistakable as other etiological factors in other cases; strains and conflicts which require analysis to reveal them are too obscure and intangible to have any certain validity. In this regard there is a close analogy to physical strain, where the line of demarcation between normal use and overstrain of muscles is quite indefinite. In many a case, when an attack of fibrositis suddenly begins during an ordinary movement it is impossible to say to what extent the movement has been the causative factor. 
In like manner, chronic rheumatic disease is often seen in parts which have been subjected to longcontinued over-use, as the shoulders of labouring men; and, in a still greater number of cases seen in middle life, it is quite difficult to say to what extent the prolonged physiological use incidental to ordinary activity has been a contributing factor. Similarly with mental stress-the business of life normally carries with it a succession of conflicts, strains, and processes of adjustment, and in the majority of cases it is impossible to say whether experiences normal to the average individual have or have not been injurious to the patient.

\section{The Need for Facts}

The attack of fibrositis experienced by the writer possessed many of the attributes regarded as typical of psychosomatic disease; in fact, a colleague frankly regarded the affliction as a neurosis. Prior to its onset, however, I had been completely free from anxiety or mental stress of any kind; later, when I was experiencing some anxiety about the future my inexplicable recovery took place.

Whenever I read of psychological explanations of fibrositis, my own experiences come to mind. My conviction, based on personal experience, is that the "vague " pains of which so many patients complain have more reality than is usually attributed to them. A debt of gratitude is due, no doubt, to the teachers who have traced the psychosomatic relationship; but the symptoms can be explained upon the basis of known somatic reactions rather than of mystic symbolism or emotional delusions.

Of all kinds of disease, the rheumatic group is the one on which modern scientific progress has made least impression. Little indeed is known, and yet we are possessed of a few facts. An outstanding fact is that these diseases are painful. If we move away from this basis of reality we may wander far into the wilderness. If our theories relating to pain do not accord with observed facts, 'twere wiser to modify the theories rather than to explain away the facts.

\section{Summary}

1. A personal experience is described in which, following a mild attack of scarlatina, the writer suffered for three months from generalized pains and muscular stiffness, entirely unaccompanied by physical signs.

2. Prevalent views upon psychogenic fibrositis are considered in the light of the writer's experiences. The idea of psychogenic pain should not be divorced from reality, for all pains are peripherally induced and subjectively appreciated.

3 . When rheumatic pain follows nervous exhaustion the etiological relationship differs little, if at all, from the case when it follows somatic disease or injury.

The Director General of Medical Services, Australian Military Forces, has kindly permitted the publication of this paper.

\section{REFERENCES}

Bramwell, E. (1930). Brit. Med. J., 1, 1

Dally, J. H. D. (1940). Lancet, 2, 405.

Ann. Rheum. Dis., 3, 56.
Good, M.(1942a). Practitioner, 148, 236.
(1942b). Ann. Rheum. Dis., 3, 118.

de Haas, A. N. L. (1941). Acta psychiat. et neurol., 16, 405.

Halliday, J. L. (1941). Ann. int. Med., 15, 666.

Kellgren J. (1942). Brit. med. J., 1, 164.

- (1939). Clin. Sci. 4, 193.

Kelly, M. (1941a). Med. J. Australia, 1, 294.

- (1941b). Brit. med. J., 1, 379.

(1942a). Med. J. Australia, 1, 311.

(1942b). Ibid., 1, 488.

(1942c). Ibid., 2, 479.

(1944a). Ibid., 1, 4

(1944b). Ibid., 1, 286

(1944b). Ibid., 1, 28

Mennell, J. B. (1938). Brit. J. Rheum., 1, 220.

Solomon, M. (1917). Med. Record, 92, 314.

Telling, W. H. M. (1935). Brit. med. J., 1, 689.

Travell, J., Rinzler, S., and Herman, M. (1942). J. Amer. med. Ass. $120,417$.

Walshe, F. M. R. (1930). Brit. med. J. 1, 126. 